\title{
WANPRESTASI DALAM PERJANJIAN KREDIT PADA LEMBAGA PERKREDITAN DESA (LPD) DI DESA BEBETIN KECAMATAN SAWAN KABUPATEN BULELENG
}

\author{
Kadek Dwinta Pradnyasar, Johannes Ibrahim Kosasih, Desak Gde Dwi Arini \\ Fakultas Hukum, Universitas Warmadewa, Denpasar - Bali, Indonesia \\ pradnyadwinta@gmail.com, johannesibrahim@rocketmail.com, arinidesa1966@gmail.com
}

\begin{abstract}
Abstrak
Perjanjian merupakan sumber terpenting yang melahirkan perikatan. Salah saru bentuk perikatan di dalam sumber-surnber perjanjian adalah dengan adanya penyaluran kredit dari pihak bank. Penelitian ini menggunakan tipe penelitian hukum empiris, teknik pengumpulan data pad a penelitian ini menggunakan penelitian lapangan. Prosedur pemberian kredit terdiri dari beberapa tahap yaitu tahap permohonan kredit, tahap survey lokasi calon debitur, tahap anal is is, tahap pemberian keputusan, dan tahap pencairan kredit. Hasil analils menemukan bahwa faktor-faktor yang menyebabkan terjadinya wanprestasi adalah faktor internal dan faktor eksternal. Faktor internal disebabkan dari pihak debitur yang tidak kredibel danjuga faktor ekonomi yang kurang stabil di tengah pandemi Covid-19 yang menyebabkan debitur tidak bisa membayar tunggakan di LPD. Faktor eksternal dari pihak LPD melakukan pendekatan secara persuasif melakukan penangan secara lanjut terhadap debitur yang bermasalah. Tujuan dari penelitian ini adalah prosedur pemberian kredit dan pengikatan perjanjian kredit yang dilakukan pada LPD Desa Pakraman Bebetin Kecamatan Sawan Kabupaten Buleleng, bagaimana faktor• faktor yang menyebabkan terjadinya wanprestasi pada LPD Desa Pakraman Bebetin Kecamatan Sawan Kabupaten Buleleng.
\end{abstract}

Kata Kunci: LPD, Perjanjian Kredit, Wanprestasi

\begin{abstract}
Agreement is the most important source that gives birth to the engagement. One form of engagement in the sources of the agreement is the extension of credit from the bank. This research uses empirical legal research type, data collection techniques in this study using field research. The procedure for granting credit consists of several stages, namely the credit application stage, the location survey stage for prospective debtors, the analysis stage, the decision-making stage, and the credit disbursement stage. The results of the analysis found that the factors that cause default are internal factors and external factors. Internal factors are caused by debtors who are not credible and also unstable economic factors in the midst of the Covid-19 pandemic which caused debtors to be unable to pay arrears in the LPD. External factors from the LPD take a persuasive approach to further handling problematic debtors. The purpose of this study is the procedure for granting credit and binding credit agreements carried out in the LPD Desa Pakraman Bebetin, Sawan District, Buleleng Regency, how are the factors that cause default in LPD Desa Pakraman Bebetin, District of Sawan, District of Buleleng.
\end{abstract}

Keyword: Credit Agreement, Default, LPD.

\section{PENDAHULUAN}

Perekonomian merupakan suaru bagian dari usaha Negara untuk memberikan kesejahteraan bagi masyarakat dan juga Negara Indonesia. Perekonomian ini terbentuk dalam suatu perdagangan, dimana ada perdagangan kecil, menengah dan perdagangan besar. Salah satu bentuk kegiatan mengenai bidang jasa tersebut adalah bidang keuangan, bidang keuangan itu dilakukan oleh lembaga bank dan juga lembaga bukan bank. Salah saru yang dilakukan lembaga keuangan di biding bank adalah usahanya dalam pemberian perkreditan, di dalam pemberian kredit ini dasarnya adalah perjanjian. Perjanjian merupakan sumber terpenting yang melahirkan perikatan.

Perikatan adalah aturan yang mengarur hubungan hukum dalam harta kekayaan antara dua pihak atau lebih, Undang-undang memberikan hak kepada saru pihak (kreditur) dan mewajibkan pihak lainnya (debitur) untuk mencapai suaru prestasi (Subekti, 1995). Salah satu bentuk perikatan di dalam sumber-sumber perjanjian adalah dengan adanya penyaluran kredit dari pihak bank, penyaluran 
kredit dari pihak bank ini merupakan salah satu upaya dari lembaga keuangan untuk mendapatkan suatu profit.

Bali merupakan salah satu Provinsi di Indonesia yang terkenal dengan adat istiadat kebudayaan yang beraneka ragam. Di samping adat istiadat dan kebudayaan untuk menciptakan perekonomian yang sejahtera maka, terdapat beberapa lembaga keuangan. Lembaga keuangan yang sangat populer di masyarakat Bali adalah lembaga keuangan mikro, salah satunya adalah Lembaga Perkreditan Desa. LPD lahir sebagai bentuk eksistensi sikap gotong royong masyarakat Desa Pakraman atau Desa Adat di Bali. Lembaga ini hampir ada di setiap Desa di seluruh Bali. Salah satu kegiatan yang dilakukan oleh LPD Desa Pakraman Bebetin adalah dengan menyalurkan kredit kepada debitur. Atau dalam hat ini adalah karma Desa guna menunjang laju perekonomian warga Desa Pakraman itu sendiri. Lembaga Perkreditan Desa seperti halnya bank, baik bank pemerintah maupun bank swasta yang ada di Indonesia adalah termasuk lembaga keuangan yang sangat penting peranannya di dalam embangunan perekonomian di pedesaan (Yasa, Rudy, \& Kusuma, 2013). (Menurut R. Tjiptonugroho), "Perjanjian kredit adalah perjanjian antara penerima dengan pemberi kredit yang memuat ketentuan ketentuan mengenai: jumlah dan cara mengangsur kredit, tujuan penggunaan kredit, jangka waktu kredit, jenis dan pengikatan jaminan kredit, cara penarikan kredit, suku bunga kredit".Dalam Lembaga Perkreditan Desa, pengertian perjanjian kredit itu lebih mengarah pada pengertian perjanjian kredit menurut Hukum Adat.

Oleh karena itu, penggunaan LPD bertujuan untuk meningkatkan taraf hidup etiket pedesaan dalam rangka mendukung pembangunan pedesaan. Pakraman khususnya dan Negara pada umurnnya sebagai salah satu contoh adalah Desa Pakraman Bebetin. Kasus yang terjadi pada LPD Desa Pakraman Bebetin terdapat wanprestasi yang dilakukan oleh debitur yang menimbulkan suatu kerugian terhadap LPD atau Lembaga Keuangan milik Desa Pakraman. Di LPD Desa Pakraman Bebetin dijumpai juga mengenai kredit yang bermasalah atau kredit macet dimana pihak debitur banyak melakukan kredit macet dikarenakan sebagian besar beralasan tidak memiliki kemampuan untuk membayar pinjaman sehingga berpengaruh terhadap modal usaha yang belum kembali di tengah situasi pandemi Covid-19 yang menyebabkan omset dari debitur menu run. Sehubungan dengan cukup banyaknya debitur yang melakukan kredit macet pada LPD di Desa Bebetin maka penulis tertarik untuk mengkaji dan meneliti terkait dengan judul "Wanprestasi Dalam Perjanjian Kredit Pada Lembaga Perkreditan Desa (LPD) di Desa Bebetin Kecamatan Sawan Kabupaten Buleleng.

Dari penelitian ini peneliti dapat dapat disimpulkan bahwa tujuan dari penelitian ini guna mengetahui prosedur pemberian kredit dan pengikatan perjanjian kredit yang dilakukan pada LPD Desa Pakraman Bebetin Kecamatan Sawan Kabupaten Buleleng,serta mengetahui faktor-faktor yang menyebabkan terjadinya wanprestasi pada LPD Desa Pakraman Bebetin Kecamatan Sawan Kabupaten Buleleng.

\section{METODE PENELITIAN}

Metode pada penelitian ini, penulis menggunakan tipe penelitian hukum empiris, merupakan tipe penelitian menggunakan fakta-fakta empiris yang diambil dari peri laku manusia, baik perilaku verbal yang didapat dari wawancara rnaupun perilaku nyata yang dilakukan rnelalui pengamatan langsung dalam perspektif empiris. Penelitian ini bersifat lapangan (field research) dengan purposive sampling terhadap LPD Desa Pakraman Bebetin, dimaksudkan untuk mengetahui pelaksanaannya, hambatanhambatan dan cara mengatasinya (Mamang, 2010). Dal am pendekatan ini dipergunakan pendekatan perundang-undangan, pendekatan konseptual, dan pendekatan yuridis sosiologis. Sumber data yang digunakan adalah sumber data utama dan sumber data tambahan. Sumber data utama adalah penelitian yang diperoleh dari sumber aslinya melalui wawancara, pendapat LPD tentang masalah kredit macet. Sumber data sekunder yaitu hasi I penelitian diperoleh melalui media perantara, atau secara tidak langsung diperoleh melalui buku, catatan, bukti atau arsip yang ada. Lokasi penelitian ini dilakukan secara langsung pada LPD Desa Pakraman Bebetin yang ada di daerah Kabupaten Buleleng yang beralamat di Banjar Dinas Desa, Desa Bebetin Kecamatan Sawan, Kabupaten Buleleng. Untuk memperoleh data yang relevan dipergunakan teknik wawancara dan studi kepustakaan. Analisis data yang dipergunakan dalam penelitian ini adalah data primer dimana penulis melakukan analisis dengan cara atau langkah• langkah yang dilakukan oleh LPD Desa Pakraman Bebetin dalam rnengatasi kredit 
macet disesuaikan dengan teknik penyelesaian kredit pada umumnya. Data sekunder pengumpulan referensi-referensi yang berkaitan dengan perjanjian. Berdasarkan analisis data penulis kemudian mengambil kesimpulan, tentang faktor-faktor yang menjadi penyebab kredit macet dan langkahlangkah penyelesaian yang dilakukan pada LPD Desa Pakraman Bebetin, (Ni Kadek Putri. 2021.)

\section{PEMBAHASAN PENELITIAN}

\section{Prosedur Pemberian Kredit dan Pengikatan Perjanjian Kredit yang Dilakukan pada LPD Desa} Pakraman Bebetin Kecamatan Sawan Kabupaten Buleleng.

Prosedur pemberian kredit pada LPD Desa Pakraman Bebetin juga menggunakan sistem yang mirip dengan Bank yaitu dengan menerapkan prinsip SC dan SP (Kosasih, 2020).

a. Prinsip SC terdiri atas :

1. Tentang watak (Character), Watak dari calon debitur merupakan salah satu faktor yang harus dipertimbangkan dan merupakan unsur yang terpenting sebelurn memutuskan memberikan kredit kepadanya.

2. Tentang modal (Capital), Hal ini diperlukan untuk mengukur tingkat rasio likuiditas dan solvabilitasnya. Rasio ini diperlukan berkaitan dengan pemberian kredit unruk jangka pendek atau jangka panjang.

3. Tentang kemampuan (Capacity), Bank harus mengetahui secara pasti atas kemampuan calon debitur dengan melakukan analisis usahanya dari waktu ke waktu.

4. Tentang kondisi ekonorni (Condition of economic), Kondisi ekonomi ini perlu menjadi sorotan bagi bank karena akan berdampak baik secara positif atau negatif terhadap usaha calon debitur.

5. Tentang jaminan (Collateral), Jaminan yang diberikan oleh calon debitur akan diikat suaru ha katas jaminan sesuai dengan jenis jaminan yang diserahkan.

b. Prinsip SC terdiri atas:

1. Tentang penggolongan peminjam (Party), Bank perlu melakukan penggolongan calon debitur berdasarkan watak, kemampuan dan modal.

2. Tentang tujuan (Purposes, Pemberian kredit bank terhadap calon debitur patut untuk dipertimbangkan dari dampak positifnya dan dari sisi ekonomi sosial.

3. Tentang sumber pembayaran (Payment), Analis kredit setelah mempertimbangkan butir b tentang dampak positif ekonomi dan sosialnya, kemudian harus dapat memprediksi pendapatan yang akan diperoleh calon debitur dari hasil penggunaan !credit.

4. Tentang kemampuan memperoleh laba (Profitability), Merupakan kemampuan calon debitur untuk memperoleh keuntungan dari usahanya.

5. Tentang perlindungan (Protection), Analis kredit perlu rnemperhatikan agunan yang diberikan calon debitur.

Dalam pemberian kredit untuk memperoleh kepastian hukum LPD desa adatmengwi mengikatkan dirinya dengan debitur dalam pentuk perjajian kredit, dimana perjanjian kredit tersebut harus memenuhi syarat sahnya suatu perjanjian yaitu pasal 1320 KUH Perdata:

Kesepakatan, kesepakatan berati kedua belah pihak sepakat untuk mengikatkan dirinya dalam suatu perjanjian kredit Kecakapan, kecakapan adalah dikedua belah pihak telah dianggap cakap untuk membuat

suatu perjanjian kredit Suatu hal tertentu, dalam perjanjian kredit harus diterang dengan jelas objek dari

Perjanjian kredit tersebut Sebab yang halal, perjanjian kredit dibuat tidak boleh bertentangan dengan peraturan perundang-undangan yang ada (Miru, 2013).

Menurut Bapak I Made Some Artana selaku Ketua LPD Desa Pakraman Bebetin, pengikatan perjanjian kredit pada LPD Desa Pakraman Bebetin ada dua mekanisme tentang perikatan yang dilakukan di LPD Desa Pakraman Bebetin terhadap debitur sesuai agunan yang diberikan, jika agunan tersebut adalah sertipikat maka perikatannya dilakukan di Notaris melalui PPAT, jika agunannya BPKB mobil atau sepeda motor maka persyaratannya BPKP tersebut harus berusia kurang dari 5 Tahun dari Tahun pembelian mobil atau sepeda motor. Bapak I Made Some Artana juga mengatakan sebagian besar debitur memberikan jaminan berupa sertifikat tanah dikarenakan pemberian agunan dari jaminan berupa sertifikat tanah sebesar $75 \%$ dari nilai jual tanah. Sedangkan untuk jarninan BPKB pemberian agunan sebesar kurang dari 50 Juta, (Azharuddin Lathif. 2019). 


\section{Faktor-faktor Terjadinya Wanprestasi pada LPD Desa Pakraman}

Bebetin Kecamatan Sawan Kabupaten Buleleng.

1. Faktor internal penyebab timbulnya kredit macet adalah penyimpangan dalam pelaksanaan prosedur perkreditan, itikad kurang baik dari pemilik, pengurus, atau pegawai bank, lemahnya sistem adrninistrasi dan pengawasan kredit serta lemahnya informasi kredit macet (Suharnoko, 2015).

Menurut Bapak I Made Some Artana selaku Ketua LPD mengatakan karena disebabkan dari pihak debitur yang tidak kredibel dan juga faktor ekonomi debitur yang kurang stabil menyebabkan terjadinya penunggakan pembayaran, apalagi disaat pandemi seperti sekarang ini banyak sekali debitur-debitur yang tidak bisa membayar tunggakan tersebut.

2. Faktor eksternal dimana keadaan yang terjadi diluar jangkauan kemampuan debitur atau keadaan memaksa (overmacht) seperti keadaan ekonomi yang tidak stabil di tengah pandemi Covid-19.

Menurut Bapak I Made Some Artana Selaku Ketua LPD Mengatakan bahwa debitur mengalami kerugian secara tidak terduga, dari pihak LPD melakukan pendekatan secara persuasif melakukan penanganan secara kontinu kepada debitur yang berrnasalah untuk mencarikan solusi sehingga dalam proses terjadinya persoalan pembayaran dapat dicarikan jalan keluar.

Upaya-upaya penyelesaian kredit pada umumnya adalah :

1. Upaya Hukum rnelalui jalur Non Litigasi secara umum penyelesaian ini dapat dilakukan rnelalui berbagai cara antara lain :

a. Negosiasi, rnerupakan proses tawar menawar untuk mencapai

kesepakatan dengan pihak lain melalui proses interaksi, komunikasi yang dinarnis dengan tu juan untuk mendapatkan penyelesaian atau jalan keluar dari permasalahan yang sedang dihadapi oleh kedua belah pihak (Nugroho, 2009, hal. 21).

b. Mediasi (meditation) melalui sistern kompromi (compromise) di antara para pihak, sedangkan pihak ketiga yang bertindak sebagai mediator hanya sebagai penolong (Nurmaningsih, 2012).

c. Konsiliasi merupakan kelanjutan dari mediasi dalam hal ini konsiliator

menjalankan fungsi yang lebih aktif dalam mencari bentuk-bentuk penyelesaian sengketa dan menawarkannya kepada para pihak,jika para pihak dapat menyetujui solusi yang dibuat konsiliator akan menjadi resolution (Nurnaningsih, 2012).

d. Arbitrase merupakan penyelesaian sengketa yang sudah lama berkembang (Nurnaningsih, 2012).

2. Upaya Hukum Melalui Jalur Litigasi

Adalah proses penyelesaian perselisihan pengadilan semua pihak yang bersengketa saling berhadapan di pengadilan dan rnembela hak-hak mereka. Hasil akhir dari penyelesaian sengketa melalui proses pengadilan adalah keputusan rnenang atau kalah (win-lose solution) (Nurmaningsih, 2012).

Menurut Bapak I Made Some Artana selaku Ketua LPD Desa Pakraman Bebetin, menjelaskan bahwa kredit macet memang disebabkan dari debitur dan bukan dari pihak LPD. Debitur meminjam kredit untuk mernbantu kelancaran usahanya, namun karena adanya pandemi covid-19 ini mengakibatkan menurunnya omset usaha dari debitur tersebut sehingga mengalami kebangkrutan dan sisa hutang yang dipinjam tidak mampu dilunasi. Dari pihak LPD mengupayakan agar tidak terjadinya kredit macet dengan melakukan peneguran melalui telepon tetapi jika debitur tidak menghiraukan teguran dari pihak LPD maka Pihak LPD melakukan penagihan ke lapangan, dan bagian kredit melakukan rapat intern untuk membahas upaya selanjutnya agar debitur bisa membayar tunggakan. Jika debitur belum bisa melunasi tunggakan sampai batas waktu maka pihak LPD memberikan teguran berupa Surat Pemberitahuan.

\section{SIMPULAN DAN SARAN}

\section{Simpulan}

Dari penjelasan diatas dapat disimpulkan bahwa prosedur pemberian kredit dan pengikatan perjanjian kredit yang dilakukan pada LPD Desa Pakraman Bebetin Kecamatan Sawan Kabupaten Buleleng yaitu: tahap pengajuan kredit, tahap investigasi lokasi calon debitur, tahap pengambilan keputusan dan tahap pencairan kredit. Setelah diputuskan dilakukan pencairan kredit lalu penyerahan uang kepada debitur yang sudah dipotong biaya administrasi pencairan kredit, maka tahapan-tahapan dalam 
proses pemberian kredit selesai. Faktor-faktor yang menyebabkan terjadinya wanprestasi pada LPD Desa Pakraman Bebetin Kecamatan Sawan Kabupaten Buleleng yaitu: faktor internal yang disebabkan dari pihak debitur yang tidak kredibel dan juga faktor ekonomi yang kurang stabil di tengah panderni Covid-19 yang menyebabkan debitur tidak bisa membayar tunggakan di LPD. Upaya-upaya penyelesaian kredit bermasalah dari pihak LPD mengupayakan agar tidak terjadinya kredit macet dengan melakukan peneguran melalui telepon, tetapi jika tidak dihiraukan teguran dari Pihak LPD maka pihak LPD melakukan penagihan kelapangan lalu bagian kredit melakukan rapat intern untuk membahas atau meninjau upaya selanjutnya agar debitur bisa membayar tunggakan, jika debitur belum bisa melunasi tunggakannya sampai batas waktu yang ditentukan dari pihak LPD maka kreditur memberikan teguran berupa Surat Pemberitahuan.

\section{Saran}

a. Kepada Pemerintah, Pemerintah Daerah dan pihak bank BPD harus memberikan kebijakan yang pasti mengenai sistem pemberian kredit dan untuk memperketat agar LPD tidak setengah-setengah dalam mengambil tindakan apabila terjadinya wanprestasi.

b. Kepada Pihak KEPADA, Pihak LPD harus Lebih memantapkan tata cara pemberian kredit yang baik agar meminimalisir adanya wanprestasi, lebih menerapkan prinsip-prinsip SP dan SC tersebut agar pemberian kredit lebih maksimal. Dan pihak LPD juga harus mampu menyelesaikan masalah dan siap menindaklanjuti debitur sesuai dengan perjanjian yang telah disepakati.

\section{DAFTAR PUSTAKA}

Azharuddin Lathif, D. M. H. (2019). Disparitas Penyelesaian Sengketa Jalur Litigasi Pada Polis Asuransi Syariah Dan Putusan Pengadilan. Legalisasi Indonesia, 16(1).

Etta Mamang Sangaji, S. (2010). Metodologi Penelitian.

Mamang, S. E. (2010). Metodologi Penelitian Bank dan Leasing. CV Mandar Maju Kencana, Bandung.

Miru, A. (2013). Hukum Perikatan Penjelasan Makna, cetakan kelima. PT Raja Grafindo Persada, Depok.

Nugroho, A. (2009). Hukum Persaingan Usaha di Indonesia. Prenada Media, Jakarta.

Nurnaningsih, A. (2012). Mediasi Alternatif Penyelesaian sengketa Perdata di Peradilan. Raja Grafindo Persada.

Subekti, \& Suharnoko, B. (1995). Aneka Perjanjian Hukum Perjanjian Teori don Analisa Kasus. Jakarta Kencana.

Tjiptonugroho, R. (1990). Perbankan Masalah Perkreditan Penghayatan, Analisis dan Penuntun. Pradnya Paramita, Jakarta.

Yasa, P. H., Rudy, D. G., \& Kusuma, A. A. G. A. D. (2013). ). Nasabah, Perlindungan Hukum Terhadap Dana Desa, Yang Disimpan Pada Lembaga Perkreditan. 10(1).

Wati, Ni Kadek Putri Candra, N. L. M. M. dan N. M. P. S. U. (2021). Pelaksanaan Perjanjian Kredit Pada Lembaga Perkreditan Desa (Lpd) Adat Mengwi. Jurnal Analogi Hukum, 3(1), Bali. 